\title{
Evaluation of the Performance Characteristics of the Lightning Imaging Sensor
}

\author{
DAILE ZHANG AND KenNETH L. CUMmins \\ Department of Hydrology and Atmospheric Sciences, The University of Arizona, Tucson, Arizona \\ PHILLIP BITZER \\ Department of Atmospheric Science, University of Alabama in Huntsville, Huntsville, Alabama \\ WILLIAM J. KOSHAK \\ Earth Science Branch, NASA Marshall Space Flight Center, Huntsville, Alabama
}

(Manuscript received 26 September 2018, in final form 21 March 2019)

\begin{abstract}
The Lightning Imaging Sensor (LIS) that was on board the Tropical Rainfall Measuring Mission (TRMM) satellite captured optical emissions produced by lightning. In this work, we quantify and evaluate the LIS performance characteristics at both the pixel level of LIS events and contiguous clusters of events known as groups during a recent 2-yr period. Differences in the detection threshold among the four quadrants in the LIS pixel array produce small but meaningful differences in their optical characteristics. In particular, one LIS quadrant (Q1, $X \geq 64 ; Y \geq 64$ ) detects $15 \%-20 \%$ more lightning events than the others because of a lower detection threshold. Sensitivity decreases radially from the center of the LIS array to the edges because of sensor optics. The observed falloff behavior is larger on orbit than was measured during the prelaunch laboratory calibration and is likely linked to changes in cloud scattering pathlength with instrument viewing angle. Also, a two-season comparison with the U.S. National Lightning Detection Network (NLDN) has uncovered a 5-7-km north-south LIS location offset that changes sign because of periodic TRMM yaw maneuvers. LIS groups and flashes that had any temporally and spatially corresponding NLDN reports (i.e., NLDN reported the radio signals from the same group and/or from other groups in the same flash) tended to be spatially larger and last longer (only for flashes) than the overall population of groups/flashes.
\end{abstract}

\section{Introduction}

The groundwork for modern space-based lightning detection began in the 1970s through several experiments that recorded lightning waveforms from above the cloud top (Vorpahl et al. 1970; Sparrow and Ney 1971; Turman 1977, 1978; Orville and Spencer 1979). Following these efforts, a wide field-of-view optical pulse sensor (OPS) and an assortment of additional instruments (i.e., electric field change sensor, cameras, optical array sensor, and spectrometer) for recording lightning were installed on a NASA U2 aircraft to carefully examine the statistical properties of lightning cloud-top optical emissions (Christian et al. 1983; Christian and Goodman 1987). Collectively, these studies demonstrated the feasibility of employing highspeed charge-coupled device (CCD) imagers to detect

\footnotetext{
Corresponding author: Daile Zhang, dlzhang@email.arizona.edu
}

transient optical pulses produced by cloud-top lightning illuminations. Further development of the technology focused on a narrow 1-nm band around the 7774 A oxygen emission line that enabled daytime lightning detection of both cloud-to-ground (CG) and intracloud (IC) lightning flashes (Christian et al. 1992; Koshak et al. 2000; Kirkland et al. 2001; Suszcynsky et al. 2001; Boccippio et al. 2002; Koshak 2010; Chronis and Koshak 2017).

Total lightning (CG plus IC) flash detection on a large spatial scale is a shining feature of satellite-based observation and therefore has played a significant role in studying thunderstorm and lightning climatology and global and regional lightning activity (Boccippio et al. 2000; Christian et al. 2003; Cecil et al. 2014; Medici et al. 2017), as well as shedding light on application-related studies such as lightning-produced $\mathrm{NO}_{x}$ and other applications (Nesbitt et al. 2000; Bond et al. 2002; Murray et al. 2012; Koshak et al. 2014; Koshak 2017). Also, the 
total lightning flash rate is the physical quantity that is most relevant for quantifying thunderstorm intensity, as it is linked to the characteristics of the convective updraft (Deierling and Petersen 2008). Thus, space-based lightning imagers are ideal for identifying the most intense thunderstorms on Earth (Zipser et al. 2006), and quantifying the total integrated effect of electrified weather on the Earth system through the global electric circuit (Mach et al. 2011; Blakeslee et al. 2014).

Although the newly launched CCD imager called the Geostationary Lightning Mapper (GLM) on the GOES16 satellite has achieved the overall design specification of $70 \%$ of total flash detection efficiency (Goodman et al. 2013), recent studies have found that GLM showed a lower detection efficiency for small and/or short-duration flashes, especially during severe storms when the flash rate was higher (Thomas et al. 2019; Hilburn et al. 2019). Preliminary results have shown that this may be due to both scattering of the thicker cloud bodies and the shorter duration of the flashes (Zhang and Cummins 2019). Because of the short period of GLM observations to date, the underlying reasons are still being investigated. However, the large GLM pixel size (approximately $8 \mathrm{~km} \times 8 \mathrm{~km}$ ) is likely a contributing factor.

Further insight into the optical characteristics of lightning seen from space can be obtained using the Tropical Rainfall Measuring Mission (TRMM) Lightning Imaging Sensor (LIS; Christian et al. 1999). This instrument collected data over the globe for more than 17 years, and was the primary data source for the total lightning studies noted above. Given the wealth of information in the archived data, as well as a finer resolution (approximately $4 \mathrm{~km} \times 4 \mathrm{~km}$ ), LIS is an important resource to better understand the GLM data. Moreover, the LIS flight spare for TRMM is now onboard the International Space Station (ISS) to expand the limited latitudinal observation by TRMM LIS to about $\pm 55^{\circ}$ (Blakeslee and Koshak 2016). With the growing use of optical observations of lightning from space throughout the world, studying LIS calibration and performance characteristics is a first step toward improving our knowledge and understanding on how to interpret data from optical satellite-based lightning observations.

The work presented here provides the basis for a calibrated reference for optical energy from lightning as a function of region and time of day, and also clarifies the performance limitations of TRMM LIS. We first examine the characteristics of the standard LIS optical products. The impacts of a nonuniform behavior of the LIS lens/CCD system are then explored. In addition, a spatial offset in the LIS georegistered group centroid (to be introduced in section 2 a) relative to the U.S.
National Lightning Detection Network (NLDN) and its temporal variation are studied. Finally, a comparison of the characteristics between the NLDN matched groups/ flashes and total groups/flashes is discussed.

\section{Data and methodology}

\section{a. Lightning Imaging Sensor}

The LIS instrument consists of an imaging system, a focal plane assembly, a real-time signal processor and background remover, an event processor and formatter, power supply, and interface electronics (Christian et al. 1992). To detect optical signatures from lightning discharges, it employs a $128 \times 128 \mathrm{CCD}$ pixel array and a very narrow $(\sim 1 \mathrm{~nm})$ filter bandwidth centered at the 777.4-nm near-infrared lightning oxygen emission triplet. Lightning discharges are identified by using a dynamic background tracking technique described as follows. The optical pulse energy received on each pixel is accumulated over an approximate 2-ms frame integration time with an uncertainty of $250 \mu$ s at the $95 \%$ confidence level (Bitzer and Christian 2015), and the result is read out using a real-time processor that compares the optical energy of each pixel with the background illumination (Christian et al. 2003). The background slowly evolves with sun angle, clouds, ground albedo, and so on and is generated by averaging the signals over a few frames on a pixel-by-pixel basis (Christian et al. 1992). The detection threshold for each pixel is set to be high enough above the background level to reduce false triggers, and is therefore higher during the daytime because of the sunlight and lower during the nighttime. The background signal also goes through a low-pass filter to reduce the impact of light contamination from transient emissions out of the focal plane.

When a pixel signal value exceeds the dynamically changing detection background threshold, the processor identifies this pixel as a LIS event, which is the fundamental element of all LIS products (Mach et al. 2007). It is possible that multiple optical pulses occurring within the frame integration time will contribute to one event. Note that a LIS-defined event is not physically equivalent to a lightning event/occurrence reported by ground-based radio-frequency (RF) measurements, but is simply a "litup cloud pixel" that is illuminated by lightning or some other source. For simplicity and clarity, we will use "event" to only represent a LIS-reported event in this paper, but not a conventional event reported by an RF system.

Above-threshold detection of events in adjacent (i.e., side by side and/or diagonally touching) pixels during the same frame integration time defines a LIS 
group, which can be physically interpreted as the optical pattern associated with either a CG stroke or a "cloud pulse," or the entire region of the cloud top simultaneously illuminated by lightning. A LIS group may consist of one or multiple events. Once a group is identified, a group centroid is then geolocated by spatially weighting all the corresponding event locations by their reported radiance, representing the center of an optical pulse.

A method called the weighted Euclidean distance (WED) is used to identify a flash, and this approach employs temporal and spatial clustering values of $330 \mathrm{~ms}$ and $5.5 \mathrm{~km}$, respectively, based on the typical maximum interstroke interval and approximate LIS pixel size (Mach et al. 2007). The WED makes an ellipsoid surface by requiring the distance in $(x, y$, and $t)$ to be less than 1 . Hence, any new group within this shell will be considered part of the same flash. If a group is not within the space-time constraints of any earlier group, it begins a new flash. Flashes are not merged, even if later groups bridge the spatial gap between them. There is no time limit to a flash, as long as the subsequent groups are within the limits of the criteria. Finally, a flash centroid is geolocated by all the included groups. The instrument characteristics including pixel integration time, pixel spatial resolution, and signal-to-noise ratio can all affect flash clustering (Mach et al. 2007).

Note that for each collected flash, LIS measures its optical energy and provides a product called flash radiance. However, as described in Koshak (2010, their appendix), the flash radiance product provided by the Optical Transient Detector (OTD; an engineering prototype of LIS) and LIS itself is technically not flash radiance. Rather, it is a proxy to flash radiance; that is, it is the sum of the pixel solid-angle averaged spectral energy densities across each illuminated pixel from each frame for the flash plus measurement error. Nonetheless, and for simplicity, we periodically use "radiance" in referring to this product. Finally, it is important to note that the light produced by an individual CG stroke or cloud pulse may be reported by LIS over more than one 2-ms frame integration time. This can occur when the light is split across frames, when there was continuing current associated with the discharges, and/or because of cloud multiple scattering that sufficiently broadened the source duration. This will be relevant to our comparison between the two systems, discussed in section 2c.

In addition to the direct lightning observations, the TRMM LIS provided data every second to indicate the status of the instrument and data usability. It consists of four parameters, each of which is an 8-bit flag that depicts the status of the instrument, platform, external and processing, as "warning", "fatal," or "indifference" during that 1-s period (Boccippio and Christian 1998; Christian et al. 2000). Lightning data during the periods with a "fatal" flag or a selected subset of "warning" flags are not included in this study $(<0.1 \%)$. When the "attitude possibly inaccurate" in the platform alert is set high and/or the external alert is set to "indifference," the data are included because their effect on the LIS data is minimal or not known (Christian et al. 2000). In addition, LIS data provide a parameter called viewtime, which indicates how long a particular location was viewed by the LIS instrument during a single overpass (Christian et al. 2000). The viewtime of a location could be reduced because of the instrument and TRMM platform problems that were indicated by the alerts.

However, one shortcoming of LIS is its short viewing time (total duration that a location is within the satellite field of view) due to the low Earth orbit of TRMM, as it can only observe a small area on Earth for a few minutes. LIS monitored a $600 \mathrm{~km} \times 600 \mathrm{~km}$ domain for 80 to $90 \mathrm{~s}$. These values vary spatially by location on Earth [i.e., lower over the South Atlantic anomaly (SAA)] and temporally before or after the satellite was boosted to a higher orbit (Christian et al. 2000; Cecil et al. 2015; Bitzer et al. 2016). In theory, there are one or two overpasses at any region in the tropics and subtropics each day, and only about $0.1 \%-0.2 \%$ of the time that the region is within the field of view. According to Cecil et al. (2015), the total view time of TRMM LIS in the tropics between 1998 and 2013 is close to $130 \mathrm{~h}(\sim 0.1 \%)$. Even at the highest sampling areas (highest latitudes), the total view time is only about $400 \mathrm{~h}(\sim 0.3 \%)$. As a result, the chance of a lightning-active region being observed by a consistently moving satellite is quite low.

Additionally, LIS is not capable of determining flash type for individual flashes, although statistical retrieval methods can be used to discriminate flash types based on the distributions of the mean optical characteristics (Koshak 2010; Koshak and Solakiewicz 2011; Koshak 2011; Koshak and Solakiewicz 2015). Overall, the model-predicted TRMM LIS flash detection efficiency of total lightning including CG and IC flashes was initially estimated to be $88 \% \pm 9 \%$ (Boccippio et al. 2002), and afterward validated as between $70 \%$ and $90 \%$ depending on the local time of day with the highest values during the night (Cecil et al. 2014).

\section{b. National Lightning Detection Network}

The ground-based lightning locating system NLDN uses a combined time-of-arrival/direction finding technology (Cummins and Murphy 2009) to geolocate lightning CG strokes/IC pulses with high spatial accuracy, and to provide additional information on the discharges. NLDN consists of roughly 100 LS7002 sensors 
uniformly covering the contiguous United States (Nag et al. 2014). The detection efficiency and location accuracy of the NLDN has been evaluated using various datasets including video observations (Biagi et al. 2007; Cummins et al. 2014; Zhang et al. 2015), tower data (Lafkovici et al. 2006; Cramer and Cummins 2014), triggered lightning data (Jerauld et al. 2005; Nag et al. 2011; Mallick et al. 2014), and others. The NLDN is able to discriminate $\mathrm{CG}$ and IC discharges with roughly 90\% accuracy (Zhang et al. 2015; Zhu et al. 2016). During the period of 2003 through 2012, it was expected to report $90 \%-95 \%$ of all CG flashes, and some IC flashes (10\%-20\%). In 2013 (mainly from April through August), the NLDN underwent a systemwide upgrade (Nag et al. 2014; Murphy and Nag 2015), focused on improving IC flash detection. Recent studies have shown an increase of the IC flash detection efficiency to $45 \%-60 \%$ after this upgrade (Murphy and Nag 2015).

When a CG or an IC discharge is detected, the NLDN reports the primary information of its time (accurate to a few microseconds; Cummins et al. 1998), estimated location, peak current, and discharge type (IC or CG). Each detected discharge is called an NLDN report (and hereafter). Additionally, the NLDN clusters discharges into flashes based on its grouping algorithm described in Murphy and Nag (2015). It should be noted here that, for intercomparison with LIS, an NLDN report (either a cloud pulse or a ground stroke) is spatially and temporally associated with at least one LIS group, not a single LIS event. To be more precise, we will use "group level" to indicate the analysis between LIS groups and NLDN reports, and "flash level" to indicate the analysis between LIS flashes and NLDN flashes. Given that a LIS event is a single "lit up" pixel in a 2-ms time period, and has no equivalent structure in an NLDN report, LIS events are not considered in the intercomparison analyses provided here.

\section{c. Temporal and spatial matching criteria}

Since a detailed intercomparison of NLDN and TRMM LIS is not within the scope of this work, we simply evaluated each LIS group in time order, and considered it to be "matched" when any NLDN report occurred within $10 \mathrm{~ms}$ and $20 \mathrm{~km}$ of the group centroid. This is the temporal and spatial matching criteria that were used in Franklin (2013), providing clear identification of "colocated" optical emissions and NLDN reports. Also, we only allowed single matches instead of multiple matches, and hence, any matched LIS group or NLDN report was not used for other matches. For the study of LIS location offset discussed in section $3 c$, if multiple NLDN reports met the criteria, we used the closest NLDN in distance as the matched report. Note that this spatial matching algorithm can occasionally cause a mismatch when the highest-peak-current NLDN discharge in the same 2-ms time window was not the closest in distance to the calculated LIS group centroid because of light scattering. From a detailed assessment of our 2012 dataset, only $10.8 \%$ of the group-level matches had multiple NLDN reports, and only $2 \%$ had more than two matches.

Similar to the group-level analysis, the flash-level analysis is also based on the matching of LIS groups and NLDN discharges, but with larger temporal (100 vs $10 \mathrm{~ms}$ ) and spatial (30 vs $20 \mathrm{~km})$ constraints than were used for the group-level analysis. This allowed matching of noncoincident reports by the two systems that were within time-space bounds of a LIS flash. When a LIS group was matched, we noted the flash that this LIS group belonged to, using its parent ID, which is a parameter provided by LIS to point out this group and flash relationship. If any group in the same flash had a match, this LIS flash became a matched flash. Therefore, a matched LIS flash can have one or more groups that are correlated with NLDN report(s). Note that this method will not match flashes that had more than $100 \mathrm{~ms}$ between all of its LIS groups and any NLDN strokes and/or pulses.

\section{Results and discussion}

The study begins by characterizing the optical behavior of the LIS pixel array during our 2-yr study period (2012 and 2013). In 2012, there were a total of 73950727 events, composed of 16566560 groups and 1467927 flashes. Similarly, in 2013, a total of 67920937 LIS events were collected, composed of 15416684 LIS groups and 1400170 LIS flashes. As a result, the annualaverage events per group and annual average groups per flash in both years were around 4.4 and 11, respectively. However, because of the seasonal behavior, only the LIS data from the summer months (June-August) in a region from $32^{\circ}$ to $38^{\circ} \mathrm{N}$ and from $80^{\circ}$ to $120^{\circ} \mathrm{W}$ were used to compare with the NLDN coincidence for the studies including the LIS group-centroid location offsets (section 3c) and matched group/flash characteristics (section 3d).

\section{a. Pixel energy density}

There is an inconsistent sensitivity in the LIS focal plane that was caused by a compromise of the LIS design that could not be mitigated using 1990s technology (Koshak et al. 2000), in which the LIS CCD was read out as four quadrants, with each having its own signal amplifier and digital conversion hardware, and the four outputs were then combined into a single data stream for 

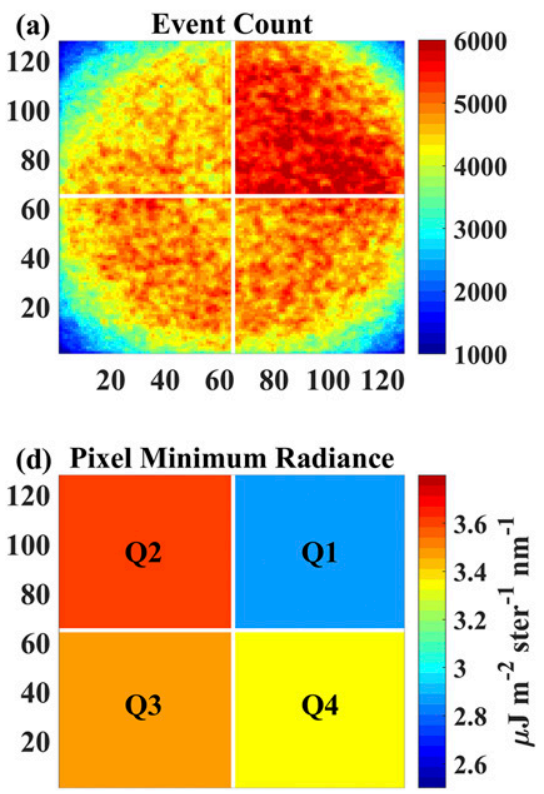

$\begin{array}{llllll}20 & 40 & 60 & 80 & 100 & 120\end{array}$

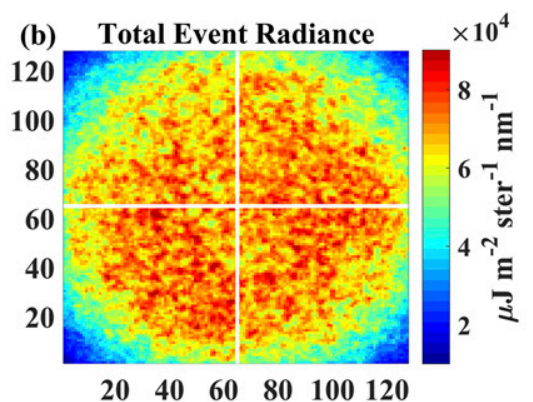

(e) Pixel Maximum Radiance

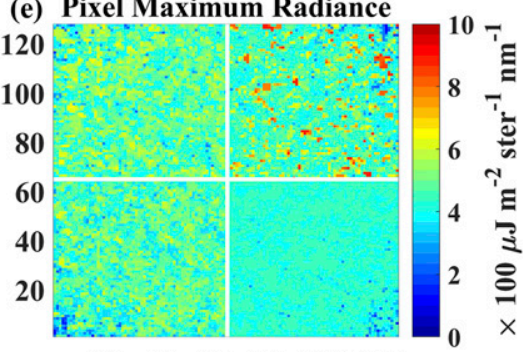

$\begin{array}{lllllll}20 & 40 & 60 & 80 & 100 & 120\end{array}$

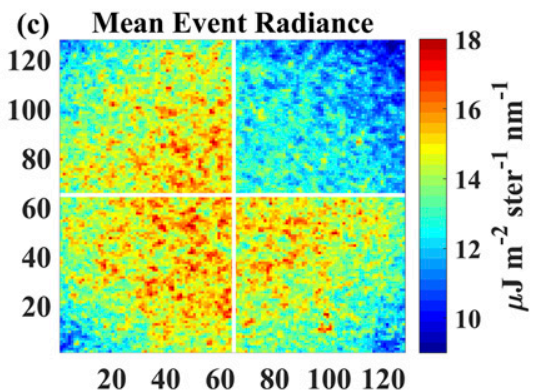

(f) Pixel 95\% Quantile Radiance

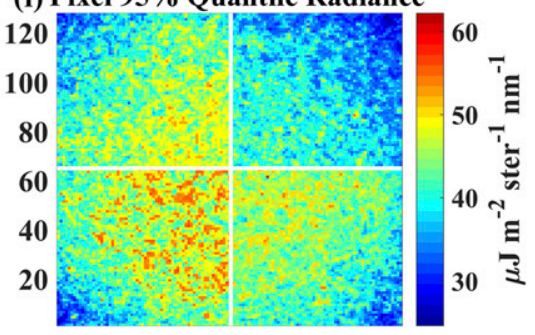

$\begin{array}{lllllll}20 & 40 & 60 & 80 & 100 & 120\end{array}$

FIG. 1. LIS $2012128 \times 128$ pixel array event energy density summary, computed separately for each pixel, indexed by CCD pixel index.

further processing. Figures 1 and 2, as well as Table 1, summarize the pixel thresholds, count of events detected, total energy density, and mean energy density across the pixel array during 2012 and 2013, respectively. Since the LIS focal plane is divided into four quadrants, the sensitivity in each quadrant, measured by the minimum (threshold) event energy density, is different. The minimum event energy density in the top-right (Q1), top-left (Q2), bottom-left (Q3), and bottom-right (Q4) quadrants were 2.866, 3.602, 3.489, and $3.349 \mu \mathrm{J} \mathrm{m}^{-2} \mathrm{sr}^{-1} \mathrm{~nm}^{-1}$, respectively, as shown in Figs. $1 \mathrm{~d}$ and $2 \mathrm{~d}$. The $20 \%$ lower Q1 was $20 \%$ more

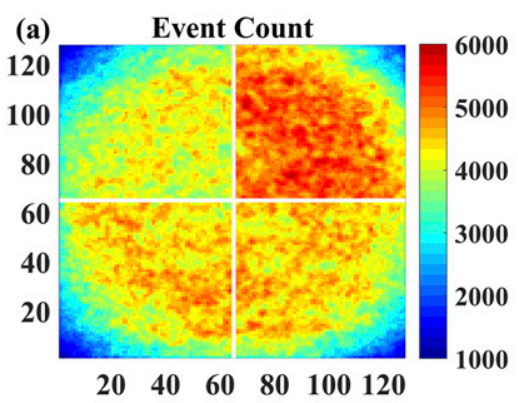

(d) Pixel Minimum Radiance

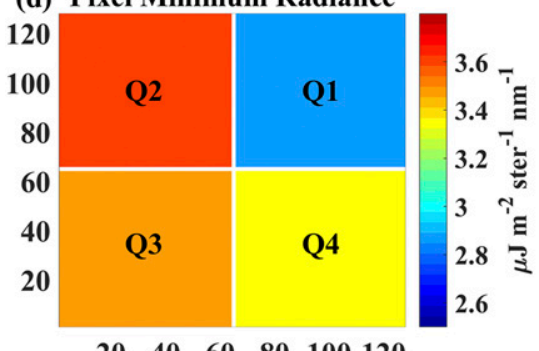

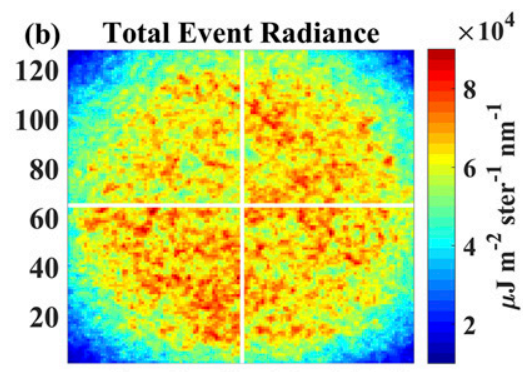

$\begin{array}{llllll}20 & 40 & 60 & 80 & 100 & 120\end{array}$

(e) Pixel Maximum Radiance

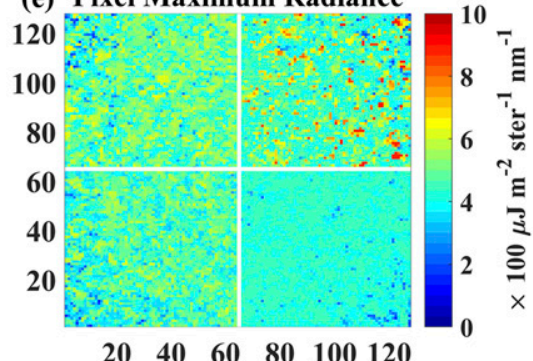

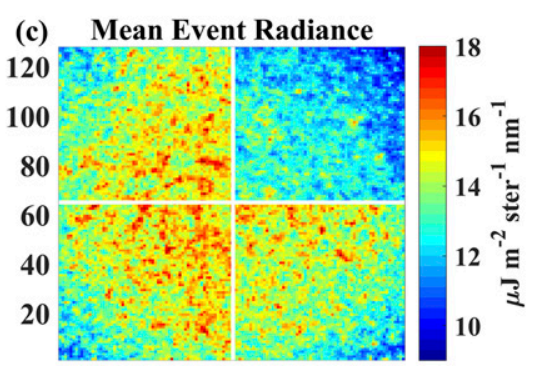

$\begin{array}{lllllll}20 & 40 & 60 & 80 & 100 & 120\end{array}$

(f) Pixel 95\% Quantile Radiance

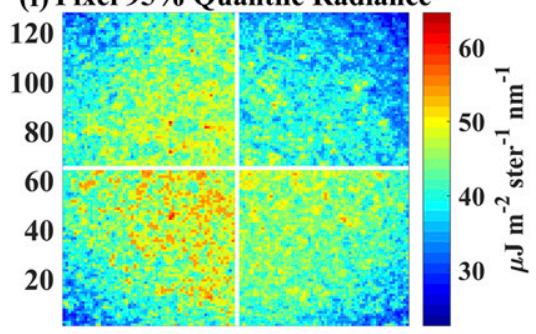

$\begin{array}{llllll}20 & 40 & 60 & 80 & 100 & 120\end{array}$

FIG. 2. LIS 2013 quadrant event energy density summary. As in Fig. 1, but for 2013. 
TABLE 1. Statistics of quadrant event energy density in 2012 (upper values) and 2013 (lower values).

\begin{tabular}{|c|c|c|c|c|}
\hline Event energy density $\left(\mu \mathrm{J} \mathrm{m}^{-2} \mathrm{sr}^{-1} \mathrm{~nm}^{-1}\right)$ & Q1 & Q2 & Q3 & Q4 \\
\hline \multirow[t]{2}{*}{ Count } & 20811776 & 16980680 & 17872388 & 18285883 \\
\hline & 18983682 & 15554597 & 16555905 & 16826753 \\
\hline \multirow[t]{2}{*}{ Minimum } & 2.87 & 3.60 & 3.49 & 3.35 \\
\hline & 2.87 & 3.60 & 3.49 & 3.35 \\
\hline \multirow[t]{2}{*}{ Maximum } & 885.0 & 646.9 & 604.8 & 463.6 \\
\hline & 885.0 & 646.9 & 604.8 & 463.6 \\
\hline \multirow[t]{2}{*}{ Dynamic range } & 882.13 & 643.30 & 601.31 & 460.25 \\
\hline & 882.13 & 643.30 & 601.31 & 460.25 \\
\hline \multirow[t]{2}{*}{ Mean } & 12.21 & 14.26 & 14.50 & 14.02 \\
\hline & 12.37 & 14.28 & 14.39 & 13.94 \\
\hline \multirow[t]{2}{*}{ Median } & 12.27 & 14.27 & 14.66 & 14.11 \\
\hline & 12.46 & 14.38 & 14.51 & 14.00 \\
\hline
\end{tabular}

sensitive and consequently reported roughly $15 \%-$ $20 \%$ more lightning events, as compared to the other quadrants. Although missing events may cause splitting of flashes depending on when/where in a flash the dim events occur (D. Buechler 2016, personal communication) and might affect the flash duration if the dim events made it to a new group or even a new flash, these situations are not very likely because of the LIS flash clustering algorithm (only $2 \%$ of the LIS flashes had one event), and so this variation in sensitivity did not have a large impact on flash characteristics. However, it certainly had an impact on the group-level optical characteristics, which will be discussed in the next section. For the mean energy densities shown in Figs. 1c and 2c, Q1 had lower values overall, as the lower threshold allowed many more low-energy events to be detected in the quadrant. However, this interquadrant nonuniformity shows little or no effect on the total energy density values, as shown in Figs. $1 b$ and $2 b$. The histograms of the energy density in each quadrant during both years are shown in Figs. 3a and 3b, and overall, there are only moderate differences in energy density distribution between the two years. Both years show $10 \%$ of the events in Q1 have energy density less than $3 \mu \mathrm{J} \mathrm{m}^{-2} \mathrm{sr}^{-1} \mathrm{~nm}^{-1}$. The percentages of the event energy density in Q1 that is larger than $10 \mu \mathrm{J} \mathrm{m}^{-2} \mathrm{sr}^{-1} \mathrm{~nm}^{-1}$ is lower than that of other quadrants, which also indicates that the lower threshold in Q1 has led to the detection of more events with lower energy density. In addition, Q2 has the highest threshold, according to Figs. $1 \mathrm{~d}$ and $2 \mathrm{~d}$. Hence, the histograms in Fig. 3 show that about 5\% fewer events were detected in Q2 with event energy density between 3 and $5 \mu \mathrm{J} \mathrm{m}^{-2} \mathrm{sr}^{-1} \mathrm{~nm}^{-1}$, compared to the other three quadrants, whereas more events with energy density higher than $5 \mu \mathrm{J} \mathrm{m}^{-2} \mathrm{sr}^{-1} \mathrm{~nm}^{-1}$ were detected in Q2.

The pixel maximum energy density (which in conjunction with the threshold, determines each pixel's dynamic range) varies among the quadrants. A roughly
$40 \%$ higher maximum-energy density value was detected in Q1 in both years, as shown in Table 1. Since these large-energy events compose a small fraction of the total events, they did not have a large impact on the quadrant mean energy density. Moreover, the dynamic range in the other quadrants was somewhat different (see Table 1). For instance, although Q4 has the second lowest threshold, it has the smallest dynamic range, as no events with energy density exceeding $500 \mu \mathrm{J} \mathrm{m}^{-2} \mathrm{sr}^{-1} \mathrm{~nm}^{-1}$ were detected. Note that these maximum energy densities in the four quadrants (so as
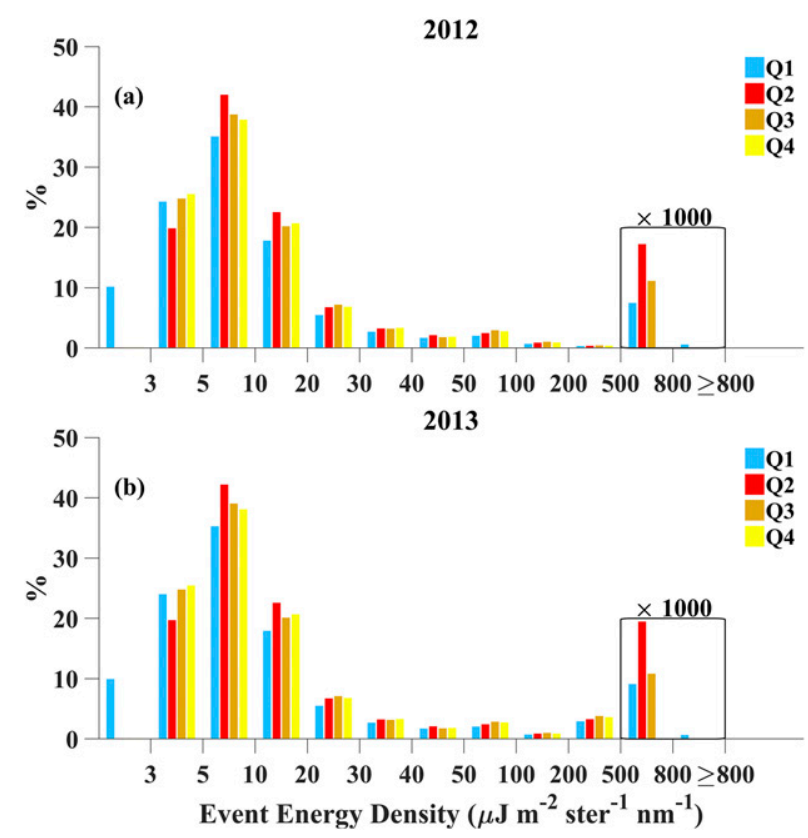

FIG. 3. (a) Histogram of LIS quadrant event energy density during 2012: Q1 (blue), Q2 (red), Q3 (orange), and Q4 (yellow) represent the four quadrants in the LIS pixel array; (b) as in (a), but for 2013 . The black boxes with " $\times 1000$ " labels enclose bars that have been enlarged 1000 times in order to better display the very high end of the distributions. 
the dynamic range) are instrumental limits, as no difference is found between the two years.

A closer look at the pixel maximum energy density shows that there is a diurnal variation (Fig. 4a), and each quadrant has its own saturation value during daytime (1000-1500 local time) and nighttime (2200-0300 local time), shown in Figs. $4 \mathrm{~b}$ and $4 \mathrm{c}$. This variation is due to the nonlinear behavior of the CCD response as a function of LIS background (BG) levels. In total, there are 41 brightness levels ranging from zero (night) to $410 \mu \mathrm{J} \mathrm{m}^{-2} \mathrm{sr}^{-1} \mathrm{~nm}^{-1}$. At night when BG is mostly zero, the maximum event energy density for the four quadrants are $383,361,398$, and $389 \mu \mathrm{J} \mathrm{m}^{-2} \mathrm{sr}^{-1} \mathrm{~nm}^{-1}$, which are shown as the "hump" features in Figs. $4 \mathrm{~b}$ and $4 \mathrm{c}$. Note that during the nighttime in Fig. $4 \mathrm{~b}$, the hump feature is more obvious than during the daytime in Fig. $4 \mathrm{c}$ because there is a higher chance of BG being zero. At $\mathrm{BG}=410$, the maximum event radiances for the four quadrants are $464,605,647$, and $885 \mu \mathrm{J} \mathrm{m}^{-2} \mathrm{sr}^{-1} \mathrm{~nm}^{-1}$, respectively, which are the "real" pixel maximum values in Figs. 1e and 2e. A sample of the nonlinear transient response curve for each quadrant at a certain BG value is given in Koshak et al. (2000, their Fig. 9).

As noted earlier, the LIS pixel array was designed to receive optical emissions from lightning pulses through a lens, scattered somewhat by intervening clouds. Therefore, the total event energy density received at each pixel is a function of the optical geometry of the cloud bodies as well as the location of the pixels relative to the boresight of the lens. Previous laboratory calibration tests have shown that the normalized pulse energy density geometrically decreases with the increasing offboresight angle from the aperture center (Boccippio et al. 2002, their Fig. 1). A similar decreasing pattern can also be derived from the observed lightning data accumulated over long time periods, as shown in Fig. 5a. The mean values have been normalized to a maximum value of 1 near the boresight $\left(\theta=0^{\circ}-10^{\circ}\right)$. All four quadrants showed a similar decreasing pattern that varies by $2 \%-3 \%$ below $35^{\circ}$ because of the limited sample size (see Fig. 5b). Note that the response function derived from our 2-yr normalized data experiences an $8 \%-10 \%$ more-rapid decrease than the previous laboratorycalibrated data (black curve) beyond $20^{\circ}$ off-boresight angle. Our preliminary hypothesis is that the morerapid falloff rate is likely a cloud effect that is not present in the calibration test laboratory. Specifically, consider an optical source a vertical distance $D$ below cloud top, but viewed at an instrument off-boresight angle $\theta$. The cloud scattering length (approximately $D \sec \theta$ ) between the cloud edge and source will be greater for larger off-boresight angles (lateral viewing), which results in greater attenuation as $\theta$ increases.
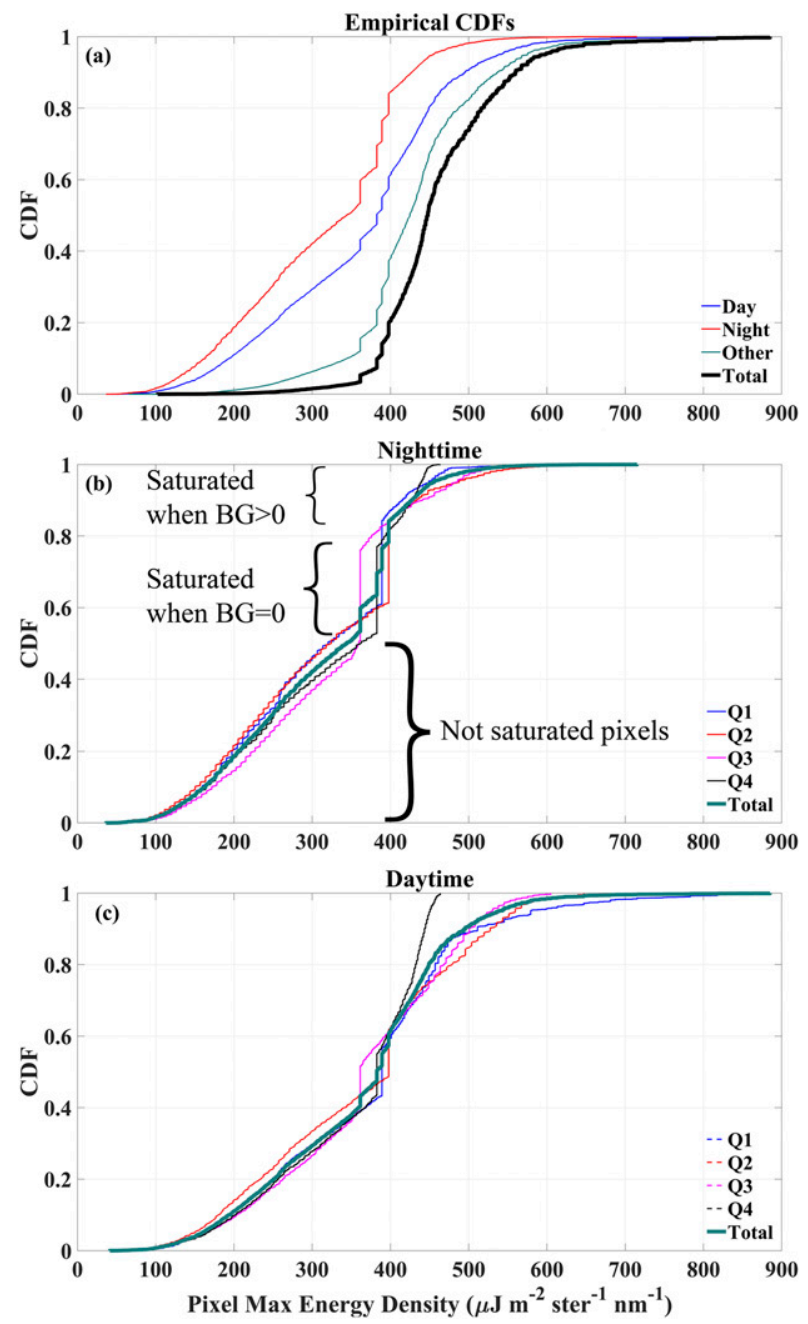

FIG. 4. Empirical cumulative distribution frequencies of the pixel maximum energy density in 2012. (a) Full $128 \times 128$ pixel array for daytime (1000-1500 LT, blue), nighttime (2200-0300 LT, red), other times (0300-1000 LT and 1500-2200 LT, green), and total times ( $24 \mathrm{~h}$, black); (b) nighttime only (2200-0300 LT) for each individual quadrant and total; (c) as in (b), but for daytime (1000-1500 LT).

Although the correction for this falloff pattern has not yet been implemented by NASA for OTD, TRMM LIS, or the ISS LIS, it is clear that the falloff in mean energy influences our overall understanding of the event optical characteristics, and is pertinent (in the case of ISS LIS) for optimizing transient threshold values.

\section{b. Group energy density and group areas}

Based on the event-group clustering algorithm (Mach et al. 2007), a LIS group is defined as one or more adjacent (neighboring or diagonal) pixels that are illuminated as events in the pixel array during the same 2-ms frame time. The difference in the dynamic range, 

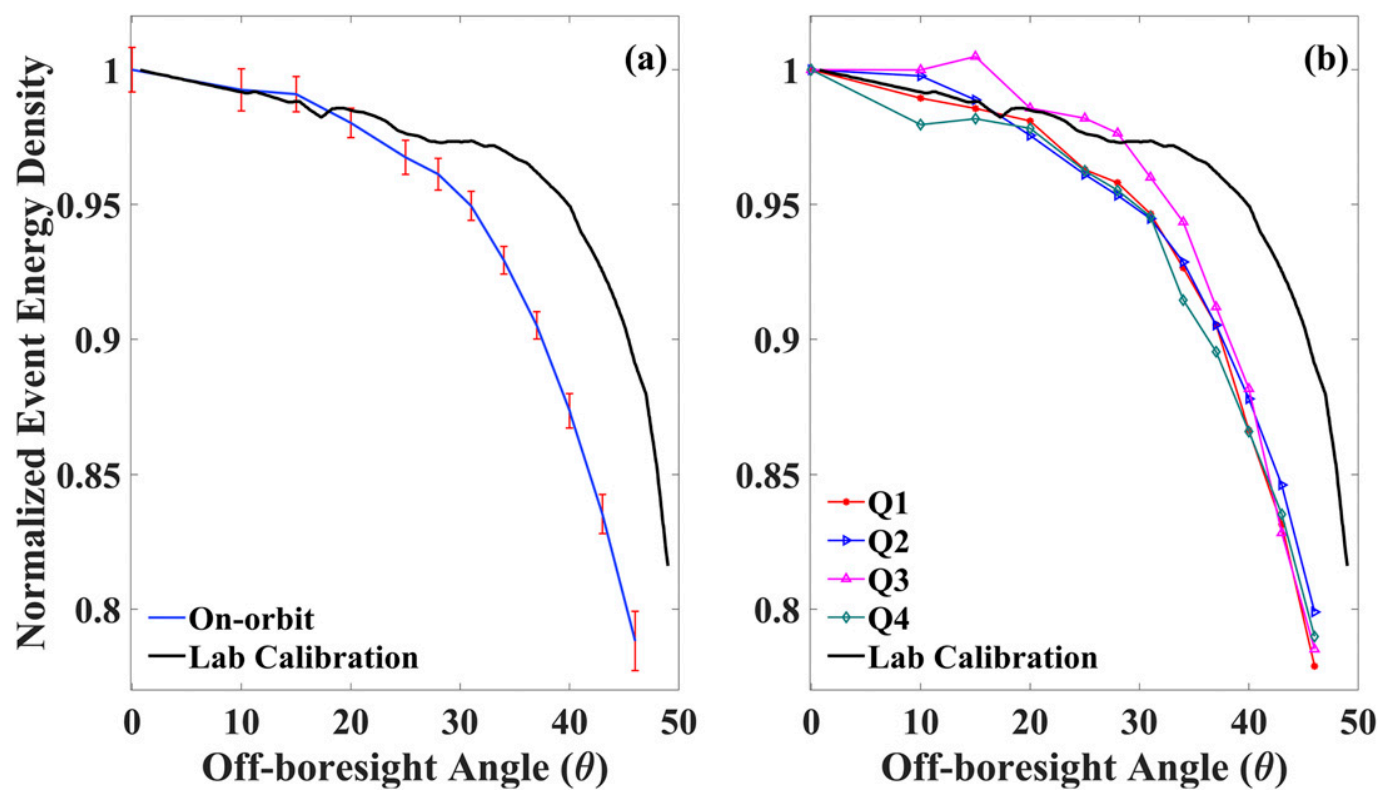

FIG. 5. Normalized pulse energy density with respect to the LIS off-boresight angle. (a) All observational data during 2012/13 (blue line) with $99 \%$ confidence intervals (red bars). The black curve is from the laboratory test data [extracted from Fig. 1 in Boccippio et al. (2002)]. (b) Marked curves are for each individual quadrant.

especially the minimum threshold, of the four quadrants may result in an inconsistency in the group characteristics, such as group energy density and group area. To explore this possibility, the group areas (GA) and group energy density (radiance product) (GR) were evaluated as follows.

If all the corresponding event pixels composing a group were in a single quadrant, we considered the group as being associated with that quadrant. The groups having event pixels in more than one quadrant were defined as "multiple." In total, $1.5 \%$ of the groups were categorized as "multiple." These groups are naturally larger than normal groups, as larger groups have more pixels in the pixel array, and hence have higher probability to cross quadrant boundaries. Statistical analyses of group parameters for both years are summarized in Table 2. The mean GA in Q1 in both years is roughly 20\% greater than for Q3 and Q4, and 15\% greater than for Q2. Since the pixel-by-pixel difference is less than $1 \%$ between the two years (see Table 2), data from the two years are combined to produce frequency histograms for the count of GA and GR for four group categories shown in Fig. 6. The normalized GA histograms in Fig. 6a show that Q1 has higher fractional values (more-frequent occurrence) than the other quadrants for areas above $100 \mathrm{~km}^{2}$, whereas the

TABLE 2. Statistics of the group characteristics in each quadrant during 2012 (upper values) and 2013 (lower values).

\begin{tabular}{|c|c|c|c|c|c|}
\hline \multirow[b]{2}{*}{ Group parameters } & \multicolumn{4}{|c|}{ Group No. } & \multirow{2}{*}{$\begin{array}{c}\text { Multiple } \\
\text { (more than one quadrant) }\end{array}$} \\
\hline & Q1 & Q2 & Q3 & Q4 & \\
\hline \multirow[t]{2}{*}{ Group count } & 4053176 & 3857475 & 4183437 & 4218681 & 253791 \\
\hline & 3748528 & 3541706 & 3944033 & 3957481 & 224936 \\
\hline \multirow[t]{2}{*}{ Mean group areas $\left(\mathrm{km}^{2}\right)$} & 125.4 & 108.4 & 105.1 & 106.4 & 207.6 \\
\hline & 124.2 & 108.7 & 103.3 & 104.6 & 208.0 \\
\hline \multirow[t]{2}{*}{$95 \%$ percentile group areas $\left(\mathrm{km}^{2}\right)$} & 365.1 & 310.0 & 300.7 & 304.9 & 632.4 \\
\hline & 360.9 & 310.7 & 295.2 & 299.1 & 637.2 \\
\hline \multirow{2}{*}{$\begin{array}{l}\text { Mean group energy density } \\
\qquad\left(\mu \mathrm{J} \mathrm{m}^{-2} \mathrm{sr}^{-1} \mathrm{~nm}^{-1}\right)\end{array}$} & 59.33 & 59.74 & 59.31 & 57.82 & 221.13 \\
\hline & 59.39 & 59.76 & 57.77 & 56.38 & 225.25 \\
\hline \multirow{2}{*}{$\begin{array}{l}95 \% \text { percentile energy density } \\
\left(\mu \mathrm{J} \mathrm{m}^{-2} \mathrm{sr}^{-1} \mathrm{~nm}^{-1}\right)\end{array}$} & 213.78 & 212.73 & 213.28 & 207.01 & 791.39 \\
\hline & 212.12 & 211.97 & 206.94 & 201.33 & 798.75 \\
\hline \multirow[t]{2}{*}{ Ratio of events to groups } & 4.9 & 4.2 & 4.1 & 4.2 & 11.2 \\
\hline & 4.8 & 4.2 & 4.0 & 4.0 & 10.8 \\
\hline \multirow{2}{*}{$\begin{array}{l}\text { Mean group energy density per group area } \\
\left(\mu \mathrm{J} \mathrm{m}^{-2} \mathrm{sr}^{-1} \mathrm{~nm}^{-1} \mathrm{~km}^{-2}\right)\end{array}$} & 0.47 & 0.55 & 0.56 & 0.54 & 1.07 \\
\hline & 0.48 & 0.55 & 0.56 & 0.54 & 1.08 \\
\hline
\end{tabular}



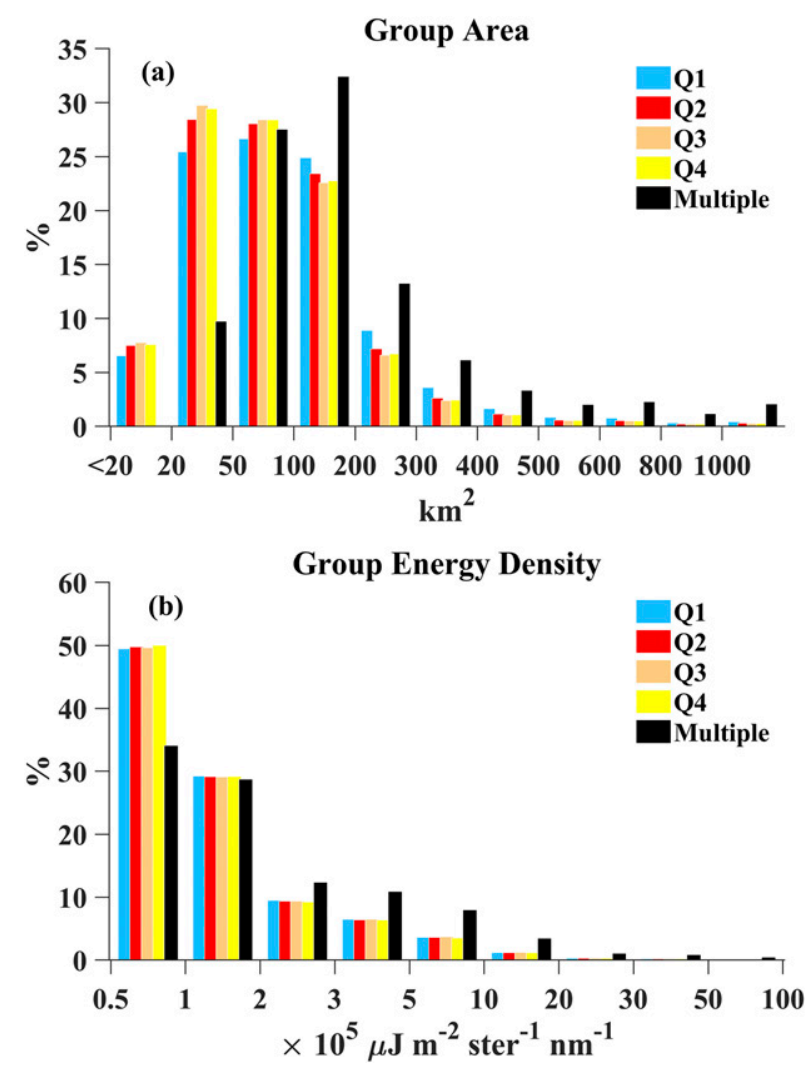

FIG. 6. (a) Histograms of quadrant group areas during 2012 and 2013 JJA, and (b) histograms of quadrant group energy density during 2012 and 2013 JJA. A quadrant group is a group with all the events within this single quadrant. "Multiple" represents those groups with events in more than one quadrant. The colors for each quadrant are consistent with those in Fig. 2d.

other three quadrants show a higher fraction for areas that are smaller than $100 \mathrm{~km}^{2}$.

The groups in Q1 are statistically larger than those in other quadrants (null hypothesis $p<0.001$ ), given the large number of observations. These differences in group size are related to the detection of more events with lower threshold in Q1. These lower-value events usually lie on the edges of a group and hence enlarge the size of the group. If the same optical pulses occurred in quadrants other than Q1, the events on the edge pixels are less likely to be detected, and the group areas may consequently be smaller. Additional evidence of this effect comes from the ratio of events to groups shown in Table 2. Although the ratios for the two years differ slightly, the ratios in an individual quadrant $(\mathrm{Q} 2, \mathrm{Q} 3$, and Q4) are close to 4, whereas roughly 0.8 more pixels or events on average contribute to groups in Q1 (4.9 in 2012 and 4.8 in 2013). The extra pixels are likely to be on the edges of the groups, as discussed above.

The mean group energy density in Q1 (Fig. 6b) does not show a clear difference when compared to the other three quadrants. As defined in the algorithm theoretical basis document for the LIS (Christian et al. 2000), group energy density is the "calibrated total radiance (energy density) of all the events associated with the group." The spatial distribution of the group energy density is consistent with the planar cloud in earlier simulation study [see plate 2(c) in Light et al. 2001]. Even though groups in Q1 tend to have more pixels/events, the energy densities in the additional pixels are low, so they do not contribute much to the sum of the total energy density. From all the results shown above, it is clear that the differences in sensitivity in the LIS pixel array can have noticeable impacts on the group parameters.

Interestingly, the mean group energy density in "multiple" quadrants is almost 4 times larger than those in a single quadrant, which indicates that groups that illuminate more than one quadrant are not only spatially larger, but also have more optical energy. In addition, a group that falls in multiple quadrants will be less likely to extend toward the edges of the array (larger off-boresight angle), where the sensitivity becomes lower. Finally, multiple-quadrant groups are actually brighter than single-quadrant groups, since the mean group energy density per group area for multiplequadrant groups are about 2 times larger than those for single-quadrant groups, as shown in Table 2.

GA percentages in multiple quadrants shown in Fig. 6a have much higher percentages for larger areas than all single quadrants. Also note that lens distortion, which causes larger pixel sizes on the edges of the pixel array, is included in the area calculation provided in the LIS dataset (Boccippio et al. 2002, see their Fig. 2). Therefore, the number of events involved in the multiquadrant groups is even larger than those in the individual quadrants, as the groups occupying multiple quadrants tend to be centered in the pixel array.

The statistics in Table 3 show that as the number of quadrants associated with a group increases, the group area, energy density, and the ratio of events to groups all increase. Groups pervading two quadrants have a mean area of about 2 times larger than those in a single quadrant (see Table 2), and a mean energy density almost 4 times higher. On average, two-quadrant groups have about 11 events, which is about 2 times more than single-quadrant groups. Three-quadrant and four-quadrant groups have even more events in the groups. The group area of threequadrant and four-quadrant groups is 3 times and 3.5-4 times larger than single-quadrant groups, respectively. The pixel-array maps for counts of groups that cross quadrant boundaries in Fig. 7 shows a bull's-eye at the center for three- and four-quadrant groups and makes a "cross" shape that follows the quadrant boundaries for two-quadrant groups. 
TABLE 3. Statistics of the multiquadrants group parameters during 2012 (upper values) and 2013 summers (lower values).

\begin{tabular}{lrrr}
\hline \hline & \multicolumn{3}{c}{ No. of quadrants } \\
\cline { 2 - 4 } \multicolumn{1}{c}{ Group parameters } & \multicolumn{1}{c}{2} & \multicolumn{1}{c}{3} & \multicolumn{1}{c}{4} \\
\hline Group count & 251464 & 1202 & 1125 \\
& 223196 & 1010 & 740 \\
Mean group areas $\left(\mathrm{km}^{2}\right)$ & 206.63 & 269.05 & 360.62 \\
& 206.93 & 307.85 & 399.07 \\
Mean group energy density & 217.54 & 502.84 & 722.38 \\
$\left(\mu \mathrm{J} \mathrm{m}^{-2} \mathrm{sr}^{-1} \mathrm{~nm}^{-1}\right)$ & 221.88 & 580.51 & 757.55 \\
Ratio of events to groups & 11.06 & 20.12 & 27.00 \\
& 10.97 & 24.57 & 32.75 \\
Mean group energy density per group & 1.05 & 1.87 & 2.00 \\
area $\left(\mu \mathrm{J} \mathrm{m}^{-2} \mathrm{sr}^{-1} \mathrm{~nm}^{-1} \mathrm{~km}^{-2}\right)$ & 1.07 & 1.89 & 1.90 \\
\hline
\end{tabular}

In addition, group energy density per group area increases with the number of associated quadrants, as shown in Table 3. Groups pervading three quadrants have about $44 \%$ larger group energy density per area, compared with those pervading only two quadrants. Groups pervading four quadrants have an even larger ratio. Combined with the information given in Table 2, it is clear that the larger groups tend to have brighter pixels, on average.

\section{c. LIS group centroid location offsets}

The location of a LIS group is the radiance-weighted centroid from all the registered events during the 2-ms period in the focal plane (Mach et al. 2007). Previous studies (Thomas et al. 2000; Rudlosky and Shea 2013; Rudlosky 2015) have shown that the average location differences between "time matched" LIS and various ground-based network observations are around 5-12 km, which is the length of 1-3 LIS pixels. In our previous study (Zhang et al. 2016), we compared the location offsets of LIS group centroids with their time matched NLDN reports (both cloud-to-ground strokes and cloud pulses) using two 1-month datasets in 2013 over a restricted region within the continental United States. The mean values of the LIS group centroid offsets during the two periods (before and after the NLDN upgrade) were essentially the same (about 5-6 km), with maximum
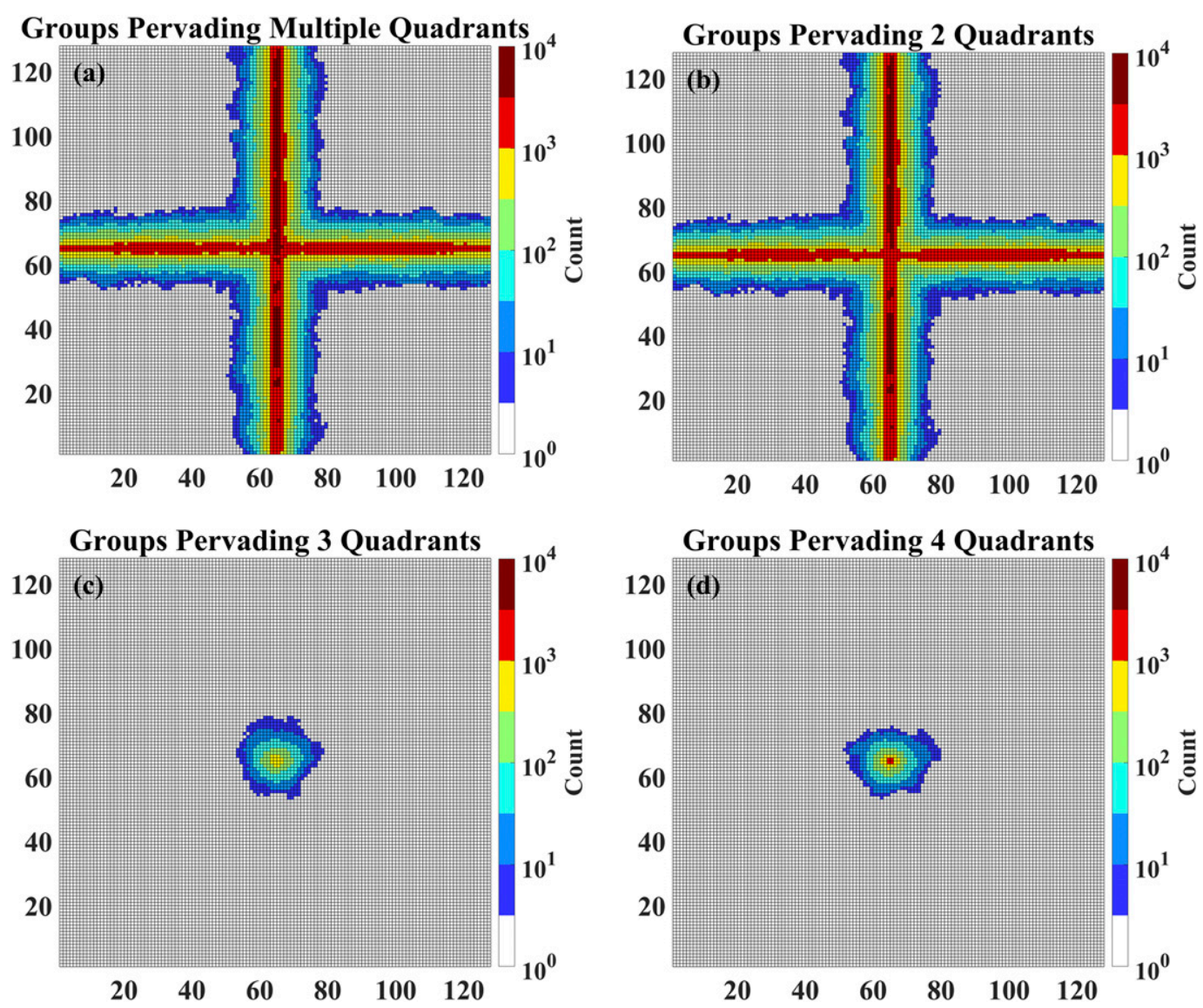

FIG. 7. 2D histograms of the number of events in multiple-quadrant groups during 2012 and 2013, indexed by CCD pixel index. (a) All multiple-quadrant groups; (b) as in (a), but for two-quadrant groups; (c) as in (a), but for three-quadrant groups; (d) as in (a), but for four-quadrant groups. 

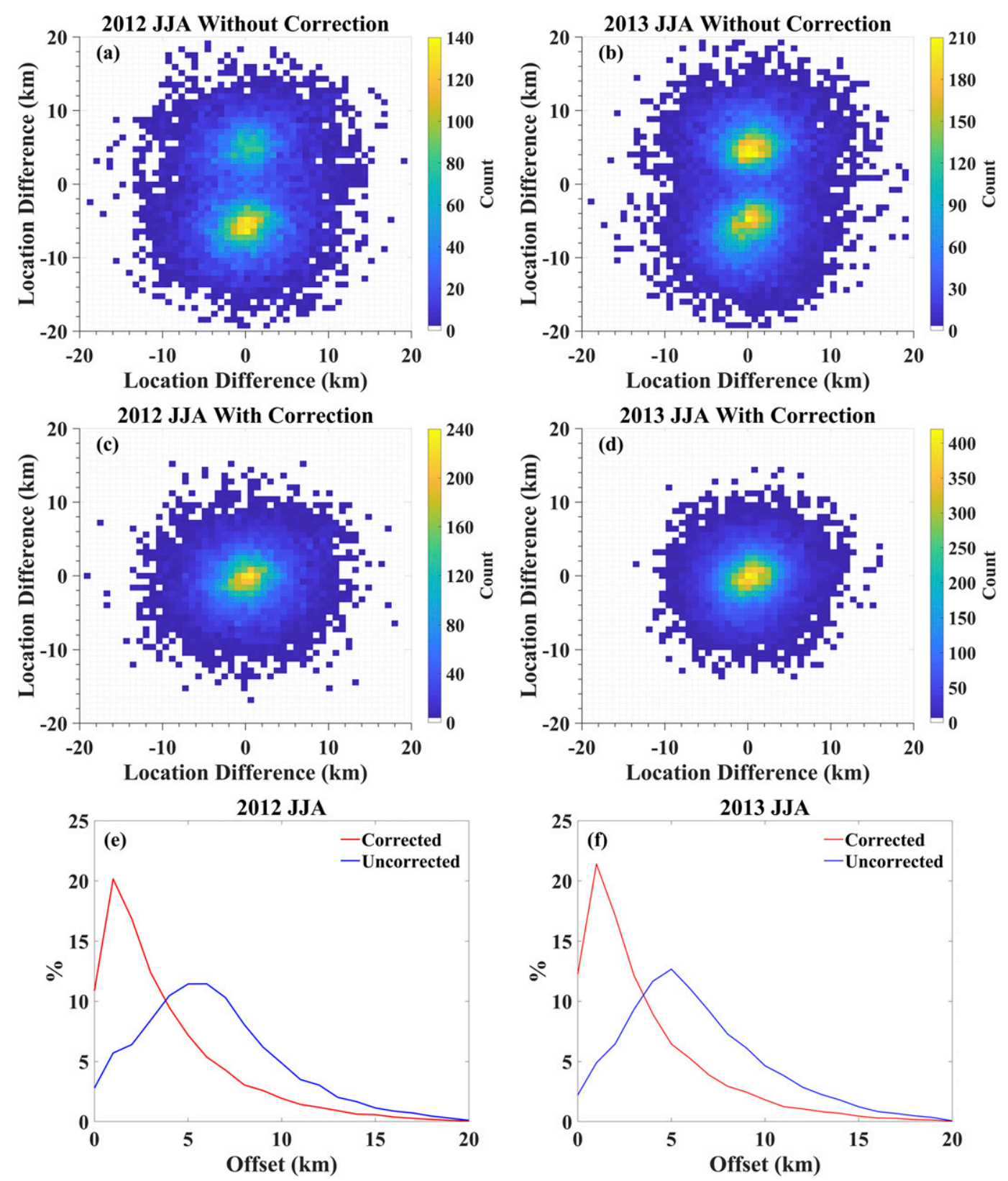

FIG. 8. (a) LIS group centroid location differences $(\mathrm{km})$ relative to the matched NLDN reports without correction during $2012 \mathrm{JJA}$; (b) as in (a), but for $2013 \mathrm{JJA}$. (c) Location differences after applying the $5 \mathrm{~km}$ offset correction during $2012 \mathrm{JJA}$; (d) as in (c), but for $2013 \mathrm{JJA}$. (e) Histograms of the corrected (red) and uncorrected (blue) LIS group location difference during $2012 \mathrm{JJA}$; (f) as in (e), but for $2013 \mathrm{JJA}$.

occurrences lying in the 4-8-km range (about 1-2 LIS pixels). We also noticed transitions in the north-south direction of these offsets (NLDN minus LIS group centroids in the analysis) at specific times, and these transitions were correlated with the TRMM satellite $180^{\circ}$ yaw maneuvers (D. Buechler 2016, personal communication). These yaw maneuvers rotated the satellite in the vertical axis (yaw direction), and occurred every 15-20 days to shade the onboard instruments from direct sunlight (Takashi and
Iguchi 2007). During the two periods in that study, two yaw maneuver operations occurred. Comparing the LIS group centroid offsets before and after the yaw maneuver, we concluded that the yaw maneuver led to a location error that could be corrected based on the date, time, and direction of the operations. The full operational information including date, time, and orbit number for the TRMM yaw maneuvers are archived by the Japan Aerospace Exploration Agency (JAXA) (JAXA 2015). 

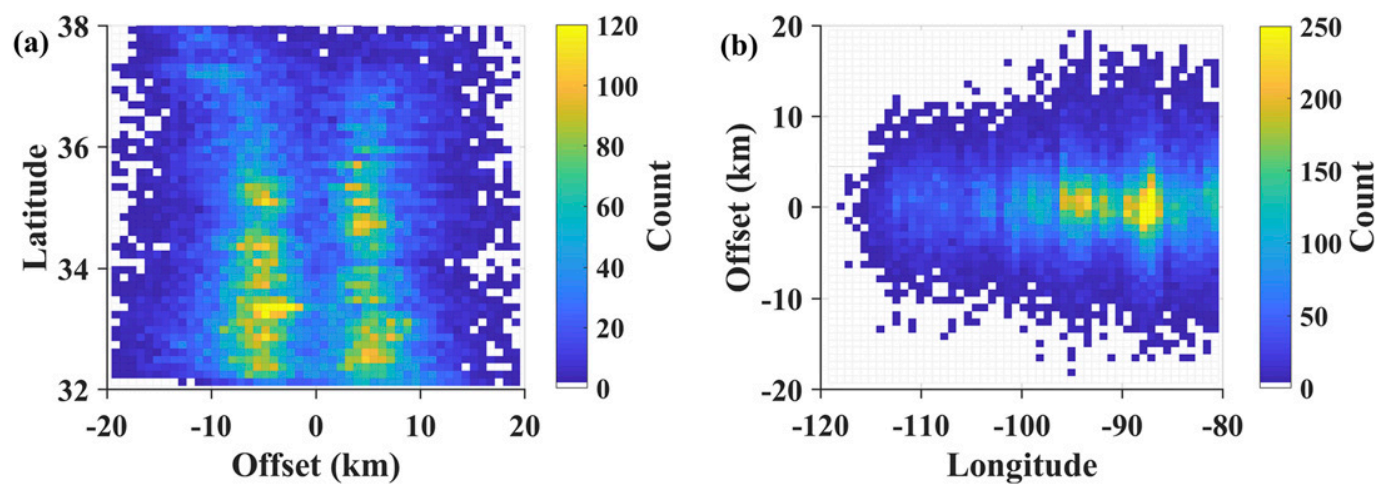

FIG. 9. (a) Variation of LIS group centroid location offsets in latitudes during 2012 and 2013 JJA; (b) as in (a), but for longitudes.

A simple but effective correction method we proposed was to add or subtract $5 \mathrm{~km}$ (average location bias; about one LIS pixel size) to/from the original data in the latitudinal direction depending on the direction of the TRMM yaw maneuver.

In this study, we have expanded our dataset to two summers to further investigate the behavior of the LIS location offsets and to revisit our previously proposed correction method. During this studied period, TRMM performed 31 yaw maneuver operations (16 times in 2012 and 15 times in 2013), which led to 32 transitions. The results for each year are shown in Figs. 8a-d as twodimensional frequency histograms. The LIS location offsets without correction displayed a maximum occurrence in the 5-7-km range (north and south) in both years, symmetrically around zero. In 2013, a total of 34062 group centroid bias samples were collected and used in the calculation, with 16629 being positive as LIS was biased to the south and 17433 being negative as LIS was biased to the north. The mean (median) value for the positive group centroid offsets was $5.87(5.19) \mathrm{km}$, while for the negative offsets they were $-6.87(-6.32) \mathrm{km}$. Similarly in 2012, a total of 20643 offset samples were collected, with 8263 being positive and 12380 being negative. Hence, the 2-yr average mean (median) positive offsets was $5.80(5.20) \mathrm{km}$, and $-6.76(-6.34) \mathrm{km}$ for the negative offsets. Note that there is less than $2 \%$ difference in the mean and median values between the two years, which shows the consistency of the offsets over the time. In addition, a previous informal comparison of the LIS group centroids location difference by one of the coauthors (P. Bitzer) showed similar results using the global Earth Networks Total Lightning Network (ENTLN) over a much larger domain. After correction using the previously proposed $\pm 5 \mathrm{~km}$, it is clear that LIS group centroids matched better with the NLDN locations (see Figs. $8 \mathrm{c}$ and $8 \mathrm{~d}$, in addition to the location offset distributions in Figs. 8e and 8f). The location difference distributions in Figs. 8e and 8f show a peak value of 1-2 km after correction, as opposed to 5-6 km before correction. The mean (median) of the location offsets with correction in the latitudinal direction during the two summers (regardless of sign) was $0.76(0.71) \mathrm{km}$, with a standard deviation of $4.93 \mathrm{~km}$. Therefore, the majority of the location differences after correction are within one LIS pixel size. Also notice that similar to our previous results (Zhang et al. 2016), the mean bias in the location offsets are mainly in the latitudinal direction. Therefore, it is recommended that this simple method be used for correcting LIS group centroids for intercomparison studies involving other geolocated datasets, since its mean and median errors are much smaller than the standard deviation. For application of LIS that requires the smallest possible location bias, the means or medians provided above should be used.

Although small, LIS location offsets could also vary as a function of latitude and longitude. As shown in Fig. 9a, there is no clear difference in the location offsets with respect to latitudes between $32.2^{\circ}$ and $35.2^{\circ} \mathrm{N}$, whereas a slight increase in the location offsets with increasing latitude is seen above $36^{\circ} \mathrm{N}$. This phenomenon may be due to the increasing LIS pixel size and reduced pixel sensitivity at the edges of the focal plane. Consequently, to correct those LIS groups detected at higher latitudes, a value other than $5 \mathrm{~km}$ might be needed. In addition, there is some variation of the location offsets below $36^{\circ} \mathrm{N}$. These variations came from individual storms on different days, which shows the uncertainty due to the small number of observations in some regions. In general, the longitudinal offsets (regardless of signs) show a slight decrease from the east to the west over the continental United States (Fig. 9b). Also, the longitude errors depend on ascending/descending nature of the orbit and the yaw orientation, but in all cases is much less than the latitudinal bias. The mean (median) of the longitudinal offsets during the two years 
TABLE 4. Statistics of the group parameter comparison between all groups and temporally and spatially matched groups during 2012 and 2013 summers.

\begin{tabular}{lrc}
\hline \multicolumn{1}{c}{ Group parameters } & Overall & Matched \\
\hline Mean energy density $\left(\mu \mathrm{J} \mathrm{m}^{-2} \mathrm{sr}^{-1} \mathrm{~nm}^{-1}\right)$ & 53.94 & 84.26 \\
$\begin{array}{l}\text { Median energy density } \\
\quad\left(\mu \mathrm{J} \mathrm{m}^{-2} \mathrm{sr}^{-1} \mathrm{~nm}^{-1}\right)\end{array}$ & 19.13 & 29.40 \\
$10 \%$ quantile energy density & 4.43 & 5.73 \\
$\quad\left(\mu \mathrm{J} \mathrm{m}^{-2} \mathrm{sr}^{-1} \mathrm{~nm}^{-1}\right)$ & & \\
$90 \%$ quantile energy density & 113.07 & 185.04 \\
$\quad\left(\mu \mathrm{J} \mathrm{m}^{-2} \mathrm{sr}^{-1} \mathrm{~nm}^{-1}\right)$ & 101.89 & 155.87 \\
Mean area $\left(\mathrm{km}^{2}\right)$ & 66.91 & 94.38 \\
Median area $\left(\mathrm{km}^{2}\right)$ & 21.65 & 27.07 \\
$10 \%$ quantile area $\left(\mathrm{km}^{2}\right)$ & 210.40 & 349.03 \\
$90 \%$ quantile area $\left(\mathrm{km}^{2}\right)$ & 4.08 & 6.28 \\
Mean child count & 3 & 4 \\
Median child count & 1 & 1 \\
$10 \%$ quantile child count & 8 & 14 \\
$90 \%$ quantile child count & & \\
\hline
\end{tabular}

is $-0.06(-0.11) \mathrm{km}$ with a standard deviation of $4.97 \mathrm{~km}$, which is comparable to the latitudinal offsets with corrections. Noted that the ISS LIS also has a location offset caused by the yaw maneuver, and preliminary results show that the location offset for the uncorrelated data is about $6-6.5$ and $2-2.5 \mathrm{~km}$ for the correlated data (Blakeslee et al. 2018; R. Blakeslee 2018, personal communication).

\section{d. Matched groups/flashes characteristics}

Since the act of matching between the networks will limit the datasets to what is seen in common, the lightning parameters associated with temporally and spatially matched LIS groups and flashes could differ from the population as a whole. A statistical comparison of the characteristics between the NLDN-matched LIS and the total LIS (matched plus not matched) at both group and flash levels is summarized in Tables 4 and 5. At both levels, the mean energy density, mean area (footprint), and the event count in a group/flash (named group child count or flash grandchild count), as well as the group count in a flash at the flash level (named flash child count) showed at least $50 \%$ larger values in the matched groups than the total groups. Compared to an average of 4.08 events in the total groups, the matched groups had an average of 6.28 events. At flash level, the mean energy density for the matched and total flashes are 822.9 and $600.6 \mu \mathrm{J} \mathrm{m}^{-2} \mathrm{sr}^{-1} \mathrm{~nm}^{-1}$, respectively, resulting in a $37 \%$ higher value in the matched flashes. The mean matched flash area $\left(312.7 \mathrm{~km}^{2}\right)$ is also $22 \%$ larger than the mean total flash area $\left(255.8 \mathrm{~km}^{2}\right)$. On average, there were 2.5 more groups and 14.3 more events in the matched flashes, compared to the total flashes. Moreover, the matched flashes lasted $50 \mathrm{~ms}$ longer than the total flashes on average. These results are in general
TABLE 5. Statistics of the flash parameter comparison between all flashes and temporally and spatially matched flashes during 2012 and 2013 summers.

\begin{tabular}{lrr}
\hline \multicolumn{1}{c}{ Flash parameters } & Overall & Matched \\
\hline Mean energy density $\left(\mu \mathrm{J} \mathrm{m}^{-2} \mathrm{sr}^{-1} \mathrm{~nm}^{-1}\right)$ & 600.61 & 822.87 \\
$\begin{array}{l}\text { Median energy density } \\
\quad\left(\mu \mathrm{J} \mathrm{m}^{-2} \mathrm{sr}^{-1} \mathrm{~nm}^{-1}\right)\end{array}$ & 192.40 & 298.57 \\
$10 \%$ quantile energy density & 33.62 & 49.53 \\
$\quad\left(\mu \mathrm{J} \mathrm{m}^{-2} \mathrm{sr}^{-1} \mathrm{~nm}^{-1}\right)$ & & \\
$90 \%$ quantile energy density & 1434.00 & 2020.30 \\
$\quad\left(\mu \mathrm{J} \mathrm{m}^{-2} \mathrm{sr}^{-1} \mathrm{~nm}^{-1}\right)$ & & \\
Mean area $\left(\mathrm{km}^{2}\right)$ & 255.85 & 312.67 \\
Median area $\left(\mathrm{km}^{2}\right)$ & 181.44 & 223.90 \\
$10 \%$ quantile area $\left(\mathrm{km}^{2}\right)$ & 66.91 & 85.53 \\
90\% quantile area $\left.(\mathrm{km})^{2}\right)$ & 512.80 & 626.55 \\
Mean child count & 11.11 & 13.62 \\
Mean grandchild count & 45.40 & 59.69 \\
Mean duration $(\mathrm{ms})$ & 270.2 & 328.6 \\
Median duration $(\mathrm{ms})$ & 224.1 & 284.9 \\
\hline
\end{tabular}

accordance with a previous study (Rudlosky et al. 2017), where they compared the LIS data with the Global Lightning Dataset 360 (GLD360) between $25^{\circ} \mathrm{S}$ and $38.5^{\circ} \mathrm{N}$. They also found that the matched LIS flashes are larger and last longer than unmatched flashes. The differences in the flash energy density, flash area, flash duration, and count of group in the flashes between our results and theirs are due to the different dataset that was compared with LIS, as well as somewhat different temporal and spatial criteria in the matching process. In summary, the spatially and temporally matched groups/flashes are spatially larger and longer duration (flashes only) than the total population of groups/flashes.

Distribution histograms for matched and total group and flash parameters are shown in Fig. 10. All the characteristics showed higher percentages (on the right $y$ axis) toward the higher-value bins in the matched groups/ flashes, as compared to the total groups/flashes. Consider the group energy density for example, where the percentage of groups with larger than $100 \mu \mathrm{J} \mathrm{m}^{-2} \mathrm{sr}^{-1} \mathrm{~nm}^{-1}$ is about $17 \%$ for matched and $11 \%$ for total, indicating $6 \%$ more matched groups in this category. Conversely, there are about $8 \%$ fewer matched groups with less than $10 \mu \mathrm{J} \mathrm{m}^{-2} \mathrm{sr}^{-1} \mathrm{~nm}^{-1}$. In addition, the matched-total count ratio (on the left $y$ axis) in all group parameters show a large increase (factor of 2) from lower-value bins to higher-value bins, representing a higher proportion of the matched groups toward the higher values. Matched flashes also tend to last longer (see Fig. 10h). Interestingly, the matched fraction for group energy density (Fig. 10a) increases much more slowly than the area-related parameters (Figs. 10c and 10e). This is likely because the optical energy near the edges of 

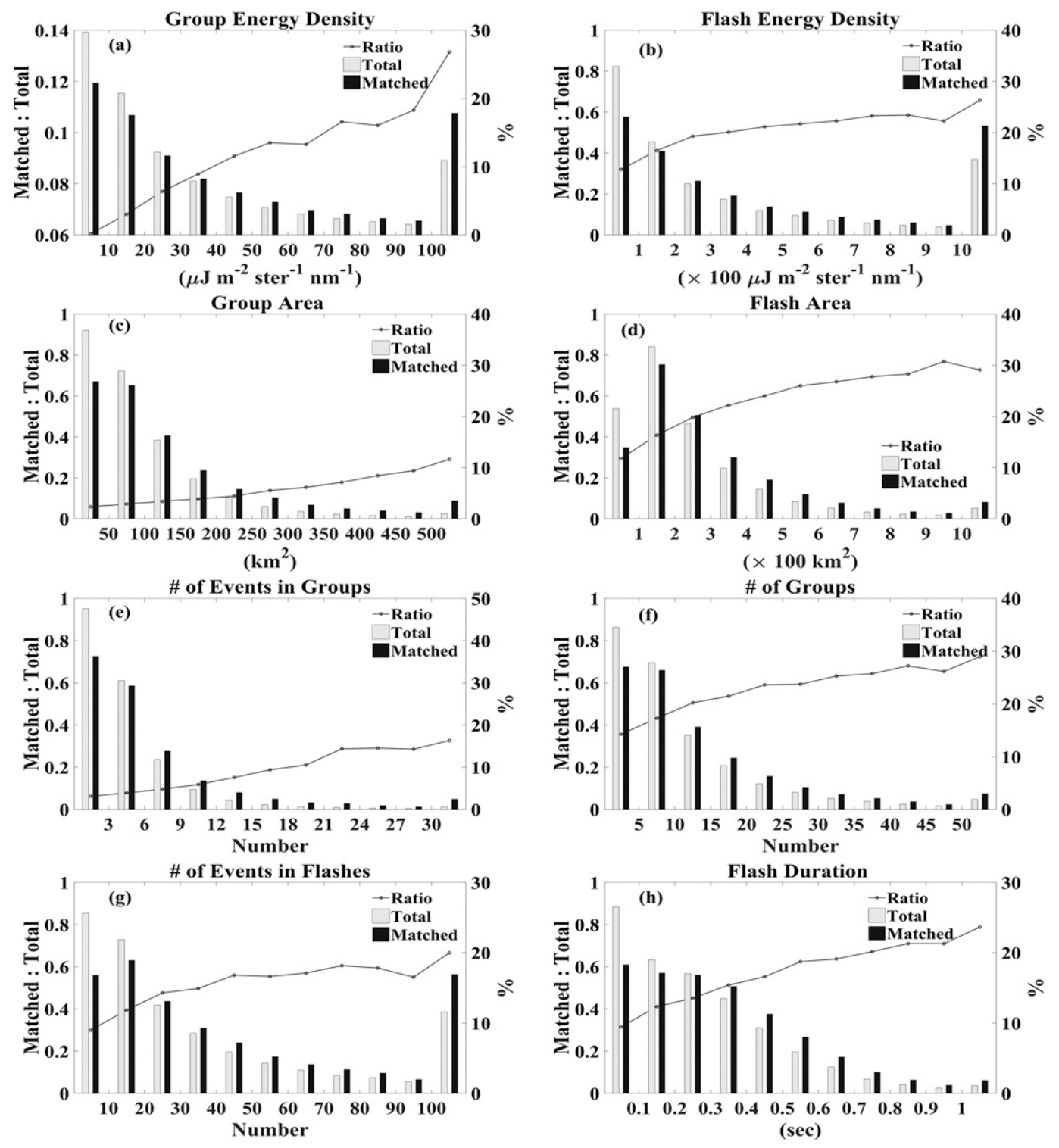

FIG. 10. Comparison of the group parameters for both matched LIS groups and total groups. The black line (left $y$ axes) shows the count ratio of the temporally and spatially matched LIS groups to the total groups in the defined ranges. The histograms (right $y$ axes) represent the count percentages of the group parameter for both matched groups (black) and total groups (white) in the defined ranges. Subplot titles indicate the specific group and flash parameters.

large groups is much lower than it is near the center of the group.

\section{Conclusions}

In this study, LIS performance characteristics at different levels are evaluated using two years of data throughout the full TRMM orbit. These findings provide important insights on the use of LIS data, and will help us to better understand the newly launched GLM and
ISS LIS, which will be of great importance for lightning observation and severe thunderstorm forecasting in the next decades. The conclusions are as follows:

1) An inconsistency of the mean event (pixel) energy in the LIS pixel array is found among the four independent quadrants. The threshold of the event energy in the four quadrants differs, which has led to meaningful differences in the mean energy and the counts of events detected. The quadrant with the lowest threshold has led to an approximate $20 \%$ 
increase in the count of events being detected and roughly $20 \%$ decrease in the mean event energy. This is due to the engineering limitation from the 1990s technology where the LIS CCD was read out as four quadrants.

2) There is a falloff pattern in the mean event energy density in the LIS pixel array as the off-boresight angle increases. Similar patterns are found in all four individual quadrants. These patterns differ from Boccippio et al. (2002) laboratory results in that they show an $8 \%-10 \%$ more rapid fall rate beyond $20^{\circ}$. It is hypothesized that this difference is not an instrumentation effect but instead may result from a longer in-cloud scattering path with increasing off-boresight angle. The falloff pattern observed from the abovementioned laboratory results is a lens/filter system instrumentation effect.

3) The quadrant (Q1) with the lowest threshold reported an average of $20 \%$ larger groups than other quadrants, as more events on the edges of the groups with lower energy were detected in that quadrant. Groups that span multiple quadrants tend to be larger than groups isolated to a single quadrant (i.e., contained more events). Groups that extended to multiple quadrants are much brighter than groups that were in a single quadrant.

4) Our 5-km correction method for the LIS location offsets that were caused by TRMM yaw maneuvers has been tested using more data and has proven to be effective. The LIS location offsets in the longitude direction are much smaller than in the latitude direction. The variation of the LIS location offsets as a function of longitude is negligible, whereas the location offsets as a function of latitude shows an increase above $36^{\circ} \mathrm{N}$, and it is probably owing to the distortion of the LIS pixel size and optical sensitivity near the edges of the focal plane.

5) The temporally and spatially matched LIS groups and flashes tend to be spatially larger and last longer (flashes only), compared to the total population of groups/flashes.

Acknowledgments. This study is sponsored by NASA Cooperative Agreement 80MSFC17M0022. This research has also been supported by the NASA ROSES-2014 NNH14ZDA001N-WEATHER program initiated by Dr. Ramesh Kakar of NASA Headquarters (retired). The authors would also like to thank the Global Hydrology Resource Center (GHRC) and Vaisala, Inc., for providing the LIS data (Blakeslee 1998) and the NLDN data, respectively. The authors acknowledge Drs. Michael Peterson and Richard Blakeslee for providing very helpful feedback. Discussions about
LIS design and implications with Drs. Dennis Buechler and Hugh Christian are also appreciated.

\section{REFERENCES}

Biagi, C. J., K. L. Cummins, K. E. Kehoe, and E. P. Krider, 2007: National Lightning Detection Network (NLDN) performance in southern Arizona, Texas, and Oklahoma in 2003-2004. J. Geophys. Res., 112, D05208, https://doi.org/10.1029/ 2006JD007341.

Bitzer, P. M., and H. J. Christian, 2015: Timing uncertainty of the Lightning Imaging Sensor. J. Atmos. Oceanic Technol., 32, 453-460, https://doi.org/10.1175/JTECH-D-13-00177.1.

_ J. C. Burchfield, and H. J. Christian, 2016: A Bayesian approach to assess the performance of lightning detection systems. J. Atmos. Oceanic Technol., 33, 563-578, https://doi.org/ 10.1175/JTECH-D-15-0032.1.

Blakeslee, R. J., 1998: Lightning Imaging Sensor (LIS) on TRMM science data. NASA Global Hydrology Center Distributed Active Archive Center, accessed 26 August 2016, https:// doi.org/10.5067/LIS/LIS/DATA201.

_- , and W. J. Koshak, 2016: LIS on ISS: Expanded global coverage and enhanced applications. Earth Observer, Vol. 28, No. 3, EOS Project Science Office, Greenbelt, MD, 4-14, https://eospso.nasa.gov/sites/default/files/eo_pdfs/ May_June_2016_color\%20508.pdf.

_ D. M. Mach, M. G. Bateman, and J. C. Bailey, 2014: Seasonal variations in the lightning diurnal cycle and implications for the global electric circuit. Atmos. Res., 135-136, 228-243, https://doi.org/10.1016/j.atmosres.2012.09.023.

,,- K. S. Virts, A. Lin, and D. E. Buechler, 2018: Lightning Imaging Sensor (LIS) on the International Space Station (ISS): Path to attaining level 1 science requirements and early results in year one. International Space Station Research and Development Conf., San Francisco, CA, NASA, O-12-02.

Boccippio, D. J., and H. J. Christian, 1998: Optical detection of lightning from space. NASA Tech. Rep., 10 pp., https:// ntrs.nasa.gov/search.jsp? $\mathrm{R}=19990008509$.

_ - S. J. Goodman, and S. Heckman, 2000: Regional differences in tropical lightning distributions. J. Appl. Meteor., 39, 2231-2248, https://doi.org/10.1175/1520-0450(2001)040<2231: RDITLD $>2.0 . C O ; 2$.

_ W. J. Koshak, and R. J. Blakeslee, 2002: Performance assessment of the Optical Transient Detector and Lightning Imaging Sensor. Part I: Predicted diurnal variability. J. Atmos. Oceanic Technol., 19, 1318-1332, https://doi.org/10.1175/ 1520-0426(2002)019<1318:PAOTOT > 2.0.CO;2.

Bond, D. W., S. Steiger, R. Zhang, X. Tie, and R. E. Orville, 2002: The importance of $\mathrm{NO}_{x}$ production by lightning in the tropics. Atmos. Environ., 36, 1509-1519, https://doi.org/10.1016/ S1352-2310(01)00553-2.

Cecil, D. J., D. E. Buechler, and R. J. Blakeslee, 2014: Gridded lightning climatology from TRMM-LIS and OTD: Dataset description. Atmos. Res., 135-136, 404-414, https://doi.org/ 10.1016/j.atmosres.2012.06.028.

,-- , and ——, 2015: TRMM LIS climatology of thunderstorm occurrence and conditional lightning flash rates. J. Climate, 28, 6536-6547, https://doi.org/10.1175/JCLI-D-15-0124.1.

Christian, H. J., and S. J. Goodman, 1987: Optical observations of lightning from a high-altitude airplane. J. Atmos. Oceanic Technol., 4, 701-711, https://doi.org/10.1175/1520-0426(1987) 004<0701:OOOLFA $>2.0 . \mathrm{CO} ; 2$. 
R. L. Frost, P. H. Gillaspy, S. J. Goodman, O. H. Vaughan Jr., M. Brook, B. Vonnegut, and R. E. Orville, 1983: Observations of optical lightning emissions from above thunderstorms using U-2 aircraft. Bull. Amer. Meteor. Soc., 64, 120-123, https://doi.org/ 10.1175/1520-0477(1983)064<0120:OOOLEF $>2.0$. CO;2.

_, R. J. Blakeslee, and S. J. Goodman, 1992: Lightning Imaging Sensor (LIS) for the Earth Observing System. NASA Tech. Rep., $42 \mathrm{pp}$.

— 11th Int. Conf. on Atmospheric Electricity, Huntsville, AL, NASA, 746-749.

— , R. J. Blakeslee, S. J. Goodman, and D. M. Mach, 2000: Algorithm theoretical basis document for the Lightning Imaging Sensor. NASA Earth Science Department Tech. Rep., 53 pp., https://eospso.nasa.gov/sites/default/files/atbd/atbd-lis-01.pdf.

— lightning as observed from space by the Optical Transient Detector. J. Geophys. Res., 108, 4005, https://doi.org/10.1029/ 2002JD002347.

Chronis, T., and W. J. Koshak, 2017: Diurnal variation of TRMM/LIS lightning flash radiances. Bull. Amer. Meteor. Soc., 98, 1453-1470, https://doi.org/10.1175/BAMS-D-16-0041.1.

Cramer, J. A., and K. L. Cummins, 2014: Evaluating location accuracy of lightning location networks using tall towers. 23rd Int. Lightning Detection Conf., Tucson, AZ, Vaisala.

Cummins, K. L., and M. J. Murphy, 2009: An overview of lightning locating systems: History, techniques, and data uses, with an in-depth look at the U.S. NLDN. IEEE Trans. Electromagn. Compat., 51, 499-518, https://doi.org/10.1109/ TEMC.2009.2023450.

— E. P. Krider, and M. D. Malone, 1998: The US National Lightning Detection Network and applications of cloud-toground lightning data by electric power utilities. IEEE Trans. Electromagn. Compat., 40, 465-480, https://doi.org/10.1109/ 15.736207.

—, D. Zhang, M. G. Quick, A. C. Garolera, and J. Myers, 2014: Performance of the US NLDN during the Kansas Windfarm2012 and 2013 field programs. 23rd Int. Lightning Detection Conf., Tucson, AZ, Vaisala.

Deierling, W., and W. A. Petersen, 2008: Total lightning activity as an indicator of updraft characteristics. J. Geophys. Res., 113, D16210, https://doi.org/10.1029/2007JD009598.

Franklin, V., 2013: An evaluation of the Lightning Imaging Sensor with new insights on the discrimination of lightning flash and stroke detectability, M.S. thesis, Dept. of Atmospheric Science, University of Alabama in Huntsville, 105 pp.

Goodman, S. J., and Coauthors, 2013: The GOES-R Geostationary Lightning Mapper (GLM). Atmos. Res., 125-126, 34-49, https://doi.org/10.1016/j.atmosres.2013.01.006.

Hilburn, K., B. Fuchs, and S. A. Rutledge, 2019: Evaluation of GOES-16 GLM to lightning mapping arrays. Ninth Conf. on the Meteorological Application of Lightning Data, Phoenix, AZ, Amer. Meteor. Soc., TJ21.3, https://ams.confex.com/ams/ 2019Annual/webprogram/Paper350881.html.

JAXA, 2015: TRMM yaw maneuver operation. Earth Observation Research Center, accessed 18 April 2018, http://www.eorc.jaxa.jp/ en/hatoyama/satellite/satdata/maneuver/Yaw_e.pdf.

Jerauld, J., V. A. Rakov, M. A. Uman, K. J. Rambo, D. M. Jordan, K. L. Cummins, and J. A. Cramer, 2005: An evaluation of the performance characteristics of the US National Lightning Detection Network in Florida using rocket-triggered lightning. J. Geophys. Res., 110, D19106, https://doi.org/10.1029/ 2005JD005924.
Kirkland, M. W., D. M. Suszcynsky, J. L. L. Guillen, and J. L. Green, 2001: Optical observations of terrestrial lightning by the FORTE satellite photodiode detector. J. Geophys. Res., 106, 33 499-33 509, https://doi.org/10.1029/2000JD000190.

Koshak, W. J., 2010: Optical characteristics of OTD flashes and the implications for flash-type discrimination. J. Atmos. Oceanic Technol., 27, 1822-1838, https://doi.org/10.1175/ 2010JTECHA1405.1.

_ 2011: A mixed exponential distribution model for retrieving ground flash fraction from satellite lightning imager data. J. Atmos. Oceanic Technol., 28, 475-492, https://doi.org/ 10.1175/2010JTECHA1438.1.

__, 2017: Lightning NOx estimates from space-based lightning imagers. 16th Annual Community Modeling and Analysis System Conf., Chapel Hill, NC, University of North Carolina at Chapel Hill.

_ , and R. J. Solakiewicz, 2011: Retrieving the fraction of ground flashes from satellite lightning imager data using CONUSbased optical statistics. J. Atmos. Oceanic Technol., 28, 459-473, https://doi.org/10.1175/2010JTECHA1408.1.

$\longrightarrow$, and - 2015: A method for retrieving the ground flash fraction and flash type from satellite lightning mapper observations. J. Atmos. Oceanic Technol., 32, 79-96, https://doi.org/ 10.1175/JTECH-D-14-00085.1.

— M. F. Stewart, H. J. Christian, J. W. Bergstrom, J. M. Hall, and R. J. Solakiewicz, 2000: Laboratory calibration of the Optical Transient Detector and the Lightning Imaging Sensor. J. Atmos. Oceanic Technol., 17, 905-915, https://doi.org/ 10.1175/1520-0426(2000)017<0905:LCOTOT >2.0.CO;2.

— B. Vant-Hull, E. W. McCaul, and H. S. Peterson, 2014: Variation of a lightning NOx indicator for national climate assessment. 15th Int. Conf. on Atmospheric Electricity, Norman, OK, Amer. Geophys. Union.

Lafkovici, A., A. M. Hussein, W. Janischewskyj, and K. L. Cummins, 2006: Performance analysis of the North American Lightning Detection Network using CN Tower lightning data. 19th Int. Lightning Detection Conf., Tucson, AZ, Vaisala.

Light, T. E., D. M. Suszcynsky, M. W. Kirkland, and A. R. Jacobson, 2001: Simulations of lightning optical waveforms as seen through clouds by satellites. J. Geophys. Res., 106, 17 103-17 114, https://doi.org/10.1029/2001JD900051.

Mach, D. M., H. J. Christian, R. J. Blakeslee, D. J. Boccippio, S. J. Goodman, and W. L. Boeck, 2007: Performance assessment of the Optical Transient Detector and Lightning Imaging Sensor. J. Geophys. Res., 112, D09210, https:// doi.org/10.1029/2006JD007787.

_ circuit implications of combined aircraft storm electric current measurements and satellite-based diurnal lightning statistics. J. Geophys. Res., 116, D05201, https://doi.org/10.1029/ 2010JD014462.

Mallick, S., and Coauthors, 2014: Performance characteristics of the NLDN for return strokes and pulses superimposed on steady currents, based on rocket-triggered lightning data acquired in Florida in 2004-2012. J. Geophys. Res. Atmos., 119, 3825-3856, https://doi.org/10.1002/2013JD021401.

Medici, G., K. L. Cummins, D. J. Cecil, W. J. Koshak, and S. D. Rudlosky, 2017: The intracloud lightning fraction in the contiguous United States. Mon. Wea. Rev., 145, 4481-4499, https://doi.org/10.1175/MWR-D-16-0426.1.

Murphy, M., and A. Nag, 2015: Cloud lightning performance and climatology of the U.S. based on the upgraded U.S. National Lightning Detection Network. Seventh Conf. on 
the Meteorological Applications of Lightning Data, Phoenix, AZ, Amer. Meteor. Soc., 8.2, https://ams.confex.com/ams/ 95Annual/webprogram/Paper262391.html.

Murray, L. T., D. J. Jacob, J. A. Logan, R. C. Hudman, and W. J. Koshak, 2012: Optimized regional and interannual variability of lightning in a global chemical transport model constrained by LIS/OTD satellite data. J. Geophys. Res., 117, D20307, https://doi.org/10.1029/2012JD017934.

Nag, A., and Coauthors, 2011: Evaluation of US National Lightning Detection Network performance characteristics using rockettriggered lightning data acquired in 2004-2009. J. Geophys. Res., 116, D02123, https://doi.org/10.1029/2010JD014929.

—, M. J. Murphy, K. L. Cummins, A. E. Pifer, and J. A. Cramer, 2014: Recent evolution of the US National lightning Detection Network. 23rd Int. Lightning Detection Conf., Tucson, AZ, Vaisala.

Nesbitt, S. W., R. Zhang, and R. E. Orville, 2000: Seasonal and global NOx production by lightning estimated from the Optical Transient Detector (OTD). Tellus, 52B, 1206-1215, https://doi.org/10.3402/tellusb.v52i5.17098.

Orville, R. E., and D. W. Spencer, 1979: Global lightning flash frequency. Mon. Wea. Rev., 107, 934-943, https://doi.org/ 10.1175/1520-0493(1979)107<0934:GLFF>2.0.CO;2.

Rudlosky, S. D., 2015: Evaluating ENTLN performance relative to TRMM/LIS. J. Oper. Meteor., 3, 11-20, https://doi.org/ 10.15191/nwajom.2015.0302.

— relative to TRMM/LIS. Geophys. Res. Lett., 40, 2344-2348, https://doi.org/10.1002/grl.50428.

_ - M. J. Peterson, and D. T. Kahn, 2017: GLD360 performance relative to TRMM/LIS. J. Atmos. Oceanic Technol., 34, 1307-1322, https://doi.org/10.1175/JTECH-D-16-0243.1.

Sparrow, J. G., and E. P. Ney, 1971: Lightning observations by satellite. Nature, 232, 540-541, https://doi.org/10.1038/232540a0.

Suszcynsky, D. M., T. E. Light, S. Davis, J. L. Green, and J. L. L. Guillen, 2001: Coordinated observations of optical lightning from space using the FORTE photodiode detector and CCD imager. J. Geophys. Res., 106, 17 897-17 906, https://doi.org/ 10.1029/2001JD900199.

Takashi, N., and T. Iguchi, 2007: Analysis of densely observed TRMM/PR data during 180-degree yaw maneuver. Geoscience and Remote Sensing Symp., Barcelona, Spain, IEEE, 3914-3919, https://doi.org/10.1109/IGARSS.2007.4423700.

Thomas, R. J., P. R. Krehbiel, W. Rison, T. Hamlin, D. J. Boccippio, S. J. Goodman, and H. J. Christian, 2000: Comparison of ground-based 3-dimensional lightning mapping observations with satellite-based LIS observations in Oklahoma. Geophys. Res. Lett., 27, 1703-1706, https://doi.org/10.1029/ 1999GL010845.

, D. R. MacGorman, E. C. Bruning, and M. A. Stanley, 2019: Evaluation of the GOES-R Geostationary Lightning Mapper (GLM) using ground-based Lightning Mapping Array (LMA) observations. Ninth Conf. on the Meteorological Application of Lightning Data, Phoenix, AZ, Amer. Meteor. Soc., TJ21.4, https://ams.confex.com/ams/ 2019Annual/webprogram/Paper354699.html.

Turman, B. N., 1977: Detection of lightning superbolts. J. Geophys. Res., 82, 2566-2568, https://doi.org/10.1029/JC082i018p02566.

1978: Analysis of lightning data from the DMSP satellite.

J. Geophys. Res., 83, 5019-5024, https://doi.org/10.1029/ JC083iC10p05019.

Vorpahl, J. A., J. G. Sparrow, and E. P. Ney, 1970: Satellite observations of lightning. Science, 169, 860-862, https://doi.org/ 10.1126/science.169.3948.860.

Zhang, D., and K. L. Cummins, 2019: Ground- and space-based observations of horizontally-extensive lightning flashes. Ninth Conf. on the Meteorological Application of Lightning Data, Phoenix, AZ, Amer. Meteor. Soc., TJ20.2, https:// ams.confex.com/ams/2019Annual/meetingapp.cgi/Paper/350971.

_, - _ and A. Nag, 2015: Assessment of cloud lightning detection by the US National Lightning Detection Network using video and Lightning Mapping Array observations. Seventh Conf. on the Meteorological Applications of Lightning Data, Phoenix, AZ, Amer. Meteor. Soc., 7.1, https://ams.confex.com/ams/95Annual/webprogram/ Paper262568.html.

,,,--- M. Murphy, and P. Boccippio, 2016: Evaluation of the National Lightning Detection Network upgrade using the Lightning Imaging Sensor. 24th Int. Lightning Detection Conf., San Diego, CA, Vaisala.

Zhu, Y., V. A. Rakov, M. D. Tran, and A. Nag, 2016: A study of National Lightning Detection Network responses to natural lightning based on ground truth data acquired at LOG with emphasis on cloud discharge activity. J. Geophys. Res. Atmos., 121, 14 651-14 660, https://doi.org/ 10.1002/2016JD025574.

Zipser, E. J., D. J. Cecil, C. Liu, S. W. Nesbitt, and D. P. Yorty, 2006: Where are the most intense thunderstorms on Earth? Bull. Amer. Meteor. Soc., 87, 1057-1072, https://doi.org/ 10.1175/BAMS-87-8-1057. 